\title{
Efficacy of the structured life review and the short-term life review on the spiritual well-being of terminally ill cancer patients
}

\author{
Michiyo Ando ${ }^{1}$, Tatsuya Morita ${ }^{2}$ \\ ${ }^{1}$ Faculty of Nursing, St. Mary’s College, Kurume, Japan; andou@st-mary.ac.jp \\ ${ }^{2}$ Department of Palliative and Supportive Care, Palliative Care Team, and Seirei Hospice, Seirei Mikatahara General Hospital, \\ Shizuoka, Japan
}

Received 27 November 2009; revised 4 January 2010; accepted 20 January 2010.

\begin{abstract}
GOALS: The aims of this study were to evaluate the treatment efficacy of the structured life review interviews and the Short-Term Life Review on the spiritual well-being of terminally ill cancer patients, in order to improve patients' quality of life. SUBJECTS and METHODS: Participants were patients in palliative care units in Japan. In the study 1 , the structured life review interviews were conducted with 12 patients. They completed the QOL scale of the SELT-M (Skalen zur Erfassung von Lebens qualitat bei Tumorkranken-Modified Version) questionnaire before and after the interviews. In the study 2 , the Short-Term Life Review was conducted with $\mathbf{3 0}$ patients. They reviewed their lives in the first session and they confirmed the contents in the album based on the life review in the second session. Duration of the treatment was one week. Measurement instruments included Functional Assessment Chronic Illness TherapySpiritual (FACIT-Sp). RESULTS: After the structured life review, the mean overall QOL score and Spirituality subscale score of the SELT-M significantly increased, from $2.57 \pm 0.61$ to 3.58 $\pm 1.0(p=0.013)$ and $2.57 \pm 0.61$ to $3.14 \pm 2.25$ $(P=0.023)$, respectively. After the Short-Term Life Review, the mean FACIT-Sp scores significantly increased from $16 \pm 8.2$ to $24 \pm 7.1$. CONCLUSION: Both the structured life review and the Short-Term Life Review may be effective in improving the spiritual well-being of terminally ill cancer patients, being higher feasibility for the Short-Term Life Review. We need to use these therapies understanding characteristics of each therapy.
\end{abstract}

Keywords: Psychotherapy; Life Review; Terminally Patients; Spiritual Well-Being

\section{INTRODUCTION}

Meaning of life or meaning of existence is an important for human, and it is called spirituality. World Health Organization demonstrates that spirituality is an important factor for human's quality of life. From the study of Japanese terminally ill cancer patients, Murata \& Morita [1] defined spiritual well-being as meaning of life and peaceful of mind, and psycho-existential sufferings as loss of meaning of life or meaning of existence. Although terminally ill cancer patients often experience psycho-existential sufferings, there have been few interventions for these problems. The present study describes an intervention to elevate spiritual well-being in terminally ill cancer patients.

Butler [2] reported that the life review process is a mean of reintegration and can give new significance and meaning to an individual's life. It is defined as "the progressive return to consciousness of prior experience, which can be re-evaluated with the intention of resolving and integrating past conflict, thereby giving new significance to one's life." A life review is a type of reminiscence therapy [2]. Reminiscence itself is an activity of life review or reminiscence therapy. Reminiscence is an interpersonal or communicative psychosocial process that can be carried out individually or in groups [3]. Previous studies have shown the effects of life review on depression [4-6], self-esteem [4], and life satisfaction [7].

There are relatively few studies concerning life review interviews for cancer patients, particularly in the form of empirical studies, though there are some studies. To use life review effectively in the clinical situation, we had to know the efficacy of life review empirically. We are reviewing two empirical studies [8,9].

\section{STUDY 1 STRUCTURED LIFE REVIEW}

\subsection{Purpose}

In the Study 1, we evaluate the treatment efficacy of the 
structured life review interviews on the spiritual wellbeing of terminally ill cancer patients.

\subsection{Methods}

\subsubsection{Participants}

Participants were patients with incurable cancer receiving specialized care in the palliative care unit of a general hospital in Japan. The inclusion criteria for this study were 1) the patient had incurable cancer, 2) the patient was 20 years of age or older, and 3) the primary physicians were in agreement that the patient would benefit from the psychological interventions. Exclusion criteria were, 1) the patients had strong physical symptoms, 2) the patients had cognitive impairment. During 6 month study periods, a total of 21 patients were recruited from the primary physicians; however 9 patients were later excluded from this study for various reasons. Thus, 12 patients ( 2 males, 10 females) finally participated in the study. The patients' ages ranged from 54 to 82, with a mean of 63. The primary tumor sites were breast $(\mathrm{n}=$ $3)$, liver $(n=2)$, colon $(n=2)$, lung $(n=2)$, thyroid $(n=$ $1)$, stomach $(n=1)$, and gallbladder $(n=1)$.

\subsubsection{Interventions and Outcome Measurements} The interviewer was a clinical psychologist. The interview procedure entailed a structured life review interview [7] in which patients reviewed their own childhood, adolescence, adult life, and current situation along Erikson' development stages [10]. Some of the questions asked were 1) Please tell me about your childhood, 2) What do you remember to be the most impressive events in your childhood?, and 3) How do you feel now when you review those impressive events (Table 1). Four sessions were planned for each patient, addition to one session for making relationships between a patient and the interviewer. Interviews were conducted in the dayroom or at the bedside. The patient reviews were recorded in the form of notes taken during or immediately after the session.

To evaluate the spiritual well-being, we used the

Table 1. The question items in the structured life review.

\begin{tabular}{cl}
\hline Times & \multicolumn{1}{c}{ Examples of question items } \\
\hline 1 & $\begin{array}{l}\text { Making relationships and listening to patients' feeling now } \\
\text { Theme: feeling life in the hospitals, problems, etc. } \\
\text { Child period: } \\
\text { Theme: parents, home town, family members, playing, } \\
\text { etc. } \\
\end{array}$ \\
& $\begin{array}{l}\text { Young Adult period: } \\
\text { Theme: study, work, human-relation in social life, etc. }\end{array}$ \\
& $\begin{array}{l}\text { Adult period: } \\
\text { Theme: marriage, born in children, role in family or } \\
\text { social life, etc. }\end{array}$ \\
& $\begin{array}{l}\text { From adult to now: } \\
\text { Theme: illness, medical treatment, human-relationships, } \\
\end{array}$ \\
\end{tabular}

SELT-M (Skalen zur Erfassung von Lebens qualitat bei Tumorkranken-Modified Version) [11]. The patients completed the Japanese version of the SETL$M$ [12] before and after the intervention. The reliability and validity of the Japanese version of the SELT-M has been reported. The SELT-M consisted of 6 subscales, namely, Physical well-being (3 items), Mood (6 items), Support (3 items), Orientation (3 items, e.g., “Today, I see many things in a more positive light”), Spirituality (3 items, e.g., "It is difficult for me to see positive meaning in my illness"), and Overall QOL (1 item). We used the overall QOL score and Spirituality subscale score in the post-interview results. Each subscale ranged from 1 to 5, with a higher score indicating a higher level of patient-perceived QOL.

The institutional review board of this hospital approved this study from both ethical and scientific aspects, and a patient gave written consent.

\subsubsection{Statistical Analysis}

In order to evaluate the treatment efficacy of life review interviews on the patient's spiritual well-being, a Wilcoxon sign rank test was conducted on the sections of the SELT-M before and after the life review interviews.

\subsection{Results}

As shown in Table 2, overall QOL and Spirituality suscale scores, in addition to Mood and Orientation suscale scores, significantly increased after the intervention.

\section{STUDY 2 SHORT-TERM LIFE REVIEW}

Although structured life review may be effective in improving the spiritual well-being of terminally ill cancer patients, the long sessions decrease the feasibility, thus we need a shorter version of life review therapy. We propose a new psychotherapy-the ShortTerm Life Review with short sessions for terminally ill cancer patients. A Short-Term Life Review involves only two sessions. Patients review or narrate their lives about questions which promote the integration of lives referring other previous studies. In the first session, patients review their lives, and the review is then recorded and edited. The therapist makes an album after the first session. In the second session, the patient and therapist view the album, and confirm the contents with appreciation.

\subsection{Purpose}

The primary aim of this study was to assess the efficacy of the Short-Term Life Review on the spiritual wellbeing, as well as anxiety, depression, sufferings, and happiness, or terminally ill cancer patients. 
Table 2. Mean scores and P value by the Wilcoxon sign rank test on scores of SELT-M.

\begin{tabular}{ccccccc}
\hline & \multicolumn{5}{c}{ SELT-M } \\
\cline { 2 - 7 } & $\begin{array}{c}\text { Physical } \\
\text { well-being }\end{array}$ & Mood & Support & Orientation & Spirituality & \multirow{2}{*}{ Overall QOL } \\
\hline \multirow{2}{*}{ Before } & $2.33(\mathrm{SD}=0.79)$ & $3.16(\mathrm{SD}=0.65)$ & $3.28(\mathrm{SD}=0.65)$ & $2.93(\mathrm{SD}=0.75)$ & $2.57(\mathrm{SD}=0.61)$ & $2.57(\mathrm{SD}=0.61)$ \\
\multirow{2}{*}{ After } & $2.80(\mathrm{SD}=1.16)$ & $3.79(\mathrm{SD}=0.74)$ & $3.61(\mathrm{SD}=0.83)$ & $3.65(\mathrm{SD}=1.03)$ & $3.14(\mathrm{SD}=2.25)$ & $3.58(\mathrm{SD}=1.0)$ \\
P value & $\mathrm{Z}=-1.02$, & $\mathrm{Z}=-2.67$, & $\mathrm{Z}=-1.18$, & $\mathrm{Z}=-2.05$, & $\mathrm{Z}=-2.23$, & $\mathrm{Z}=-2.49$, \\
& $\mathrm{P}=0.307$ & $\mathrm{P}=0.008$ & $\mathrm{P}=0.237$ & $\mathrm{P}=0.041$ & $\mathrm{P}=0.023$ & $\mathrm{P}=0.013$ \\
\hline
\end{tabular}

Table 3. Patient backgrounds.

\begin{tabular}{lll}
\hline Primary tumor site & & Gender \\
\hline Lung & $\mathrm{n}=8$ & Male $(\mathrm{n}=8)$ \\
Stomach & $\mathrm{n}=5$ & Female $(\mathrm{n}=22)$ \\
Pancreas & $\mathrm{n}=2$ & Age \\
Gallbladder & $\mathrm{n}=2$ & Mean age;74 (Total SD = 9.1) \\
Uterine & $\mathrm{n}=2$ & Martial states \\
Breast & $\mathrm{n}=1$ & Married $(\mathrm{n}=29) ;$ Widow $(\mathrm{n}=11)$, Widower $(\mathrm{n}=3)$ \\
Kidney & $\mathrm{n}=1$ & Non-married $(1)$ \\
Leukemia & $\mathrm{n}=1$ & Religion \\
Rectal & $\mathrm{n}=1$ & Christian $(\mathrm{n}=4)$ \\
Tongue & $\mathrm{n}=1$ & Buddhism $(\mathrm{n}=3)$ None $(\mathrm{n}=22)$ \\
Colon & $\mathrm{n}=1$ & ECOG-PS \\
Mesothelioma & $\mathrm{n}=1$ & 1 (n=1), 2 (n=3) \\
Myeloma & $\mathrm{n}=1$ & 3 (n $=13),(\mathrm{n}=13)$ \\
Lymphoma & $\mathrm{n}=1$ & Duration from the interview to patients' death \\
& & Mean; 67 days \\
\hline
\end{tabular}

\subsection{Methods}

\subsubsection{Participants}

The participants were cancer patients from the palliative care unit of two general hospitals and one home-care clinic. The inclusion criteria for this study were 1) patients with incurable cancer; 2) patients without cognitive impairment; 3) patients 20 years of age or older; and 4) patients for whom the primary physicians agreed would benefit from the psychological interventions. During the 11-month study period, 35 patients were recruited through primary physicians. Table 3 shows the patients' background.

\subsubsection{Intervention}

Ethical aspect of this study was validated by both the board and the ethical committee of St. Mary's Hospital and St. Mary's College.

The Short-Term Life Review has two parts. In the first part, patients review their lives, and in the second, they re-evaluate, re-construct, and appreciate their life. The interviewer was a clinical psychologist (therapist). The interview procedure was based on a structured life review interview that was conducted individually, and the patient was asked to re-evaluate both good and bad memories. Question items were mainly based on the structured life review, and some items from Chochinov et al. [13] were added. The following questions were asked in the reviewing session (Table 4):

1) What is the most important thing in your life and why? 2) What are the most impressive memories in your life ? 3)
In your life, what was the event that or the person who affected you the most? 4) What is the most important role in your life? 5) Which is the proudest moment of your life? 6) Is there anything about you that your family would need to know, are there things you would want them to tell you, and, if possible, are there things you would want them to remember? 7) What advice or word of guidance would you wish to pass on othe important people in your life or to the younger generation?

The patient's narratives were recorded, and the thera pist tried to listen to each word uttered by the patient. After the first session, the interview was first transcribed verbatim and the therapist made the album. To make the album, 1) key words in the answer to each question were selected. Words or phrases used by the patient were written in the album as often as possible; both good and bad things were included and feelings or re-framed thoughtshow he feels now-were written in the album. 2) The therapist pasted photos or drawings from various books or magazines that were related to the patients' words or phrases, to make the album more beautiful and more memory-provoking. It took a week for the treatment.

\subsubsection{Outcome Measurements}

To measure the effects of the Short-Term Life Review, we used the Japanese version of FACIT-Sp [14]. The validity and reliability of the FACIT-Sp Japanese version is well-established [15].

\subsubsection{Statistical Analysis}

To evaluate the efficacy of the Short-Term Life Review in improving the patients' spiritual well-being, the Wil- 
Table 4. The question items in the short-term life review.

Question Items
1) What is the most important thing in your life and why?
2) What are the most impressive memories in your life ?
3) In your life, what was the event that or the person who affected you the most?
4) What is the most important role in your life?
5) Which is the proudest moment of your life?
6) Is there anything about you that your family would need to know, are there things you would want them to tell you, and, if possible, are
there things you would want them to remember?

coxon signed rank test was conducted on all scores of each scale before and after the Short-Term Life Review.

\subsection{Results}

Five of the patients were excluded from this study because of unexpected deterioration in health. Thus, a total of 30 patients completed all sessions. After the ShortTerm Life Review, the mean FACIT-Sp scores significantly increased from $16 \pm 8.2$ to $24 \pm 7.1(Z=-4.2, P=$ 0.001).

\section{DISCUSSION}

\subsection{Effects of the Structured Life Review and the Short Term-Life Review}

After the structured life review, the significant increase in the SELT-M scores, as well as the Spirituality, Orientation, and Mood subscales shows the efficacy of this therapy on spiritual well-being of terminally ill cancer patients. As the Spirituality and Orientation subscale quantify the levels of the patients' meaningfulness and positive outlook, the patients may have found a meaning to life and had more positive thoughts. The significant increase in the Mood subscale for terminally ill cancer patients is accord with previous studies for elders [3-5].

After the Short-Term Life Review, the FACIT-Sp scores significantly increased. It shows the effect of this therapy on spiritual well-being of cancer patients. We confirm the efficacy of this therapy even when we compare it with the control group [16]. Adapting these process with the previous theoretical model $[17,18]$, we can explain the effects of Short-Term Life Review. A patient has a purpose or a goal for his life when he is healthy. However, when he falls into serious illness, it is often difficult for him to attain his purpose or a goal because of unexpected serious illness, and he feels much distress. In this situation, when he receives the Short-Term Life Review and he can re-think and modifies his original purpose or goals into attainable ones, he feels positive mood. Short-Term Life Review may contribute for a patient to reconstruct his life being congruent with cancer in his life.

\subsection{Feasibility}

It would be remarkable for Short-Term Life Review to have high feasibility. The percentage of patients deteriorating with this therapy was only $17 \%$, although, it was $30 \%$ for patients using the structured life review. We describe some factors related to feasibility. 1) The Short-Term Life Review is completed in a week, and this short-term intervention enables terminally ill cancer patients to complete an intervention. 2) Patients with very low functionality in ADL can participate because the patients review their lives while lying on bed. If patients' ADL is high, the Problem-solving therapy for cancer patients [19] and cognitive behavior therapy for cancer patients [20], or meaning-centered group psychotherapy [21] are also effective.

\subsection{Characteristics of Each Life Review}

There are some characteristics of each therapy. The structured life review is suitable for patients who have much time for interviews and require little cognitive load. Oppositely, The Short-Term Life review is suitable for patients who do not have much time for interviews and require a little more cognitive load. In the Short-Term Life review, a patient needs to think of his life profoundly, resulting in requiring much cognitive load. We use these therapies understanding patients' physical and mental states.

\section{CONCLUSIONS}

Both the structured life review and the Short-Term Life Review have efficacy on spiritual well-being of terminally ill cancer patients, being higher feasibility for the Shot-Term Life Review. We need to use these therapies understanding characteristics of each therapy.

\section{REFERENCES}

[1] Murata, H. and Morita, T. (2006) Conceptualization of psycho-existential suffering by the Japanese Task Force: The first step of a nationwide project. Pattern of Palliative Care, 4, 279-285. 
[2] Butler, R.N. (1974) Successful aging and the role of the life review. Journal of the American Geriatrics Society, 22, 529-535.

[3] Haight, B., Coleman, P.G., and Lord, K. (1995) The linchpins of a successful life review: Structure, evaluation, and individuality. In Haight, B.K. and Webster, J.D. (Eds) The art and science of reminiscing: theory, research, methods and applications. Bristol, P.A: Taylor \& Francis, 179-192.

[4] Haight, B., Michel, Y., and Hendrix, S. (1998) Life review: Preventing despair in newly relocated nursing home residents: Short- and long-term effects. International Journal of Aging and Human Development, 47, 119-142.

[5] Haight, B., Michel, Y., and Hendrix, S. (2000) The extended effects of the life review in nursing home residents. International Journal of Aging and Human Development, 50, 151-168.

[6] Jones, E.D. and Beck-Little, R. (2002) The use of reminiscence therapy for the treatment of depression in rural-dwelling older adults. Issues in Mental Health Nursing, 23, 279-290.

[7] Haight, B.K. (1988) The therapeutic role of a structured life review process in homebound elderly subjects. Journal of Gerontology, 43, 40-44.

[8] Ando, M., Tsuda, A., and Morita, T. (2007) A preliminary study of life review interviews on the spiritual well-being of terminally ill cancer patients. Support Care Cancer, 15, 225-231.

[9] Ando, M., Morita, T., Okamoto, T., and Ninosaka, Y. (2009) One week Short-Term Life Review interview can improve spiritual well-being of terminally ill cancer patients. Psycho-Oncology, 17, 885-890.

[10] Erikson, E.H. (1959) Identity and the life cycle. International University Press, New York.

[11] Wegberg, B.V., Bacchi, M., and Heusser, P., et al. (1998) The cognitive-spiritual dimension:-an important addition to the assessment of quality of life: Validation of a questionnaire (SELT-M) in patients with advanced cancer.
Annals of Oncology, 9, 1091-1096

[12] Ishikawa, K. (2000) Spiritual QOL. Palliat Med, 2, 173-181 (in Japanese)

[13] Chochinov, H.M., Hack, T., Hassard, T., et al. (2005) Dignity therapy: A novel psychotherapeutic intervention for patients near the end of life. Journal of Clinical Oncology, 23, 5520-5525.

[14] Peterman, A.H., Fitchett, G., Brady, M.J., et al. (2002). Measuring spiritual well-being in people with cancer: The Functional Assessment of Chronic Illness Therapy-Spiritual Well-Being Scale (FACIT-Sp), Annals of Behavioral Medicine, 24, 49-58.

[15] Noguchi, W., Ono, T., Morita, T., et al. (2004) An investigation of reliability and validity to Japanese version of Functional Assessment of Chronic Illness Therapy-Spiritual (FACIT-sp), Japan Journal of General Hospital Psychiatry, 16, 42-47

[16] Ando M, Morita T, Akechi T, et al. (2009) The efficacy of Short-Term Life Review interviews on the spiritual well-being of terminally ill cancer patients. Journal of Pain and Symptom Management, in press

[17] Park, C.L. and Folkman, S. (1997) Meaning in the context of stress and coping. Review Genel Psycholo, 1, 115-144.

[18] Folkman, S. and Greer, S. (2000) Promoting psychological well-being in the face of serious illness: when theory, research and practice inform each other. Psycho-Oncology, 9, 11-19.

[19] Nezu, A.M., Nezu, C.M., Friedman, S.H., et al. (2002). Psychosocial oncology. In Nezu A.M., Nezu C.M., Geller P.A. Eds., Health psychology, Handbook of Psychology, Wiley, 9, 121-156.

[20] Greer, S. and Moorey, S. (1997) Adjuvant psychological therapy for cancer patients. Palliat Med, 11, 240-244.

[21] Breitbert, W. (2002) Spirituality and meaning in supportive care: spirituality- and meaning-centered group psychotherapy interventions in advanced cancer. Support Care Cancer, 10, 272-280.. 